\title{
The challenges of using self-report measures with people with severe mental illness: Four participants' experiences of the research process
}

The challenges of using self-report measures with people with severe mental illness: Four participants' experiences of the research process

Authors: Jennifer Bibb ${ }^{1} \mathrm{PhD}$, Katrina Skewes McFerran ${ }^{1} \mathrm{PhD}$

${ }^{1}$ National Music Therapy Research Unit, Melbourne Conservatorium of Music, University of
Melbourne, 234 St Kilda Road, Southbank 3006, Victoria, Australia

Corresponding author:

Jennifer Bibb

National Music Therapy Research Unit

Building 862, Melbourne Conservatorium of Music

234 St Kilda Road

Southbank 3006

Victoria

Australia

bibb.jennifer@unimelb.edu.au

+61432959014

\section{Conflict of Interest}

The authors declare no known conflicts of interest.

\begin{abstract}
This study aimed to explore four mental health consumers' experiences of completing self-report outcome measures in a research project. Participants were recruited from a community mental health organisation in Melbourne and were interviewed upon completion of a mixed methods research study where they were asked to complete a series of self-report outcome measures. Descriptive phenomenological micro-analysis was used to analyse interview data and is presented along with the researchers' observations during the data collection process. Results revealed that participants
\end{abstract}


found the outcome measures cognitively challenging and the language used in the measures did not support the empowering intentions of mental health recovery. The authors suggest that the value of completing surveys for people with severe mental illness needs to be carefully considered so that the research process does not diminish other benefits of participation.

\section{Introduction}

“It's your work, but it's my life" - Julie Shaw, 1996

These powerful words spoken by Julie Shaw, depict the frustration of a participant in a mental health research study (Shaw \& Epstein, 1996). Shaw's experience as a participant in two different qualitative mental health studies illustrates the subtle differences that contribute to either feeling valued as a participant, or feeling like a rat in a laboratory. In one of the studies, Shaw was interviewed by a researcher who made her feel comfortable and asked her to select a pseudonym which was later used in published material. The researcher checked interview transcripts with Shaw before publication and valued her contribution as a participant in the research. Shaw believed this study intended to convey consumers as "whole people with distinct personalities" (p. 281). In the "lab-rat inducing" study, the researcher used the interview to 'pluck' out material that she felt matched her pre-existing beliefs (p. 282). Shaw was not given the opportunity to contribute to the research study and felt used by the researcher.

Whilst undertaking a mixed methods research study as part of my doctoral research, I became aware of the complexities facing consumers during their participation in research, particularly self-report outcome measures. As a result, I chose to include an additional question in my interviews with participants after the 
program was complete, where I asked them to specifically reflect on their experience of completing self-report outcome measures in the study. This journal article reports on these reflections.

\section{The research process and mental health participants.}

Authors have previously highlighted the need for studies which emphasise the unheard voices of mental health participants in research (Dunn, Candilis \& WeissRoberts, 2006). The psychological risks for research participants not experiencing mental illness include depression and anxiety, altered self-concept, shame, fear and embarrassment (Labott \& Johnson, 2004). Added challenges for research participants with a mental illness are feeling stressed from the unknown (Kaminsky, Roberts \& Brody, 2003), feeling intruded upon (Boothroyd, 2000), and fearing the need to reveal sensitive information (Carey et al., 2001). It is likely that these risks are amplified for people with severe mental illness (Grant, 2015), since increased symptoms are more likely to make participants feel anxious when information is asked of them during data collection (Boothroyd, 2000).

In two studies seeking mental health consumers' experiences of participating in interview research, the majority of participants (96\% Boothroyd, 2000; 86\% Grant, 2015) reported positive experiences. Participants reported being valued and respected by researchers who asked questions in a way they could understand (Grant). One participant said that the researcher, "treated [them] as an individual...not as just a statistical number" (p. 25). However, a small amount of participants in both studies experienced the research process as negative. Some participants (6.7\%; Boothroyd) felt that the questions about their mental health made them feel slightly anxious and $9 \%$ found the entire interview anxiety producing. One participant in Grant's study, described feeling pressured to answer questions that he thought did not apply to him. 
The participant felt he needed to be dishonest with the researcher in order to complete his participation in the study. It was noted by Boothroyd that the 9\% of participants who reported becoming anxious during participation in the research was nearly twice the rate of distress reported in studies using 'well' community based samples.

The inherent power imbalance that exists between researcher and participant (Muhammad et al., 2015), may make it hard for participants to feel they can exit a research study, even if they have previously understood that they are 'allowed' to, during the informed consent process (Grant, 2015). Participants report a desire to please the researcher, helping them by participating and answering questions for them even if they found the question stressful. One participant in Boothroyd's (2000) study, reported feeling pressured to participate in the research because he could not read the consent form and did not want to tell the interviewer. It is important to be aware of the potential to disempower participants through the research process and to adopt strategies to prevent this from happening.

\section{Using outcome measures in mental health research.}

Research designs using self-report outcome measures further impact participants' experiences of the research process. In a study exploring consumers' experiences of completing a standardised self-report measure of recovery (Hoy, 2014), four out of the 17 participants in the study reported a negative change in feeling state while they were completing and after completing the measure. Another study (Marshall et al., 2001) aimed to understand the subjective experience of participation in long-term outcome research of psychodynamic psychotherapy and psychoanalysis for people with affective disorders. Results revealed that participants reported "minimal negative impact" from participation with a "slight to moderate positive impact” (p. 321). After learning about participants' positive experiences of 
the research process, authors presumed that clinicians must have previously underestimated the positive benefits of participation in research for mental health consumers. However, since the study used a questionnaire to assess the impact of questionnaire based research on participants, it is difficult to believe that this is a true representation of the range of experiences resulting from this type of research.

Many researchers emphasise the importance of spending time and energy explaining questions to participants and regularly asking them how they are feeling during the research process (Boothroyd, 2000). This is believed to be especially important for participants with serious mental illness who may require more time and assistance from the researcher when completing interviews or questionnaires (Dworkin, 1992). Yet, opportunities for support are often limited for participants in quantitative studies where research protocols must be adhered to and measures must be administered in strict conditions. It may be more useful to adapt the design to suit the abilities of participants. For example, in Silverman and Leonard (2012)'s music therapy study of participants with severe mental illness, it was deemed inappropriate to use self-report instruments due to participants' overt psychotic symptoms. Instead, the researchers chose to use observational measures in order to get the most accurate representation of participants' music group preferences. Keeping the participant and their capabilities at the centre of our research, ensures a realistic representation of the clinical sample participating in the study.

The study described in this article reports on a small qualitative research project that aimed to understand how consumers with severe mental illness report on their experiences of completing standardised self-report outcome measures. The participants completed outcome measures in a different part of the study, in an attempt to measure social connectedness and wellbeing before, during and after a 10 
week music therapy program. During the research process, each of the four participants struggled to understand and complete the standardised outcome measures (the Clinical Outcomes in Routine Evaluation [CORE] questionnaire, the Perceived Cohesion in Small Groups Scale [PCiSG] and the Sense of Belonging Instrument [SOBI]). This led to a change of focus to participants' experiences of the research process.

\section{Method}

\section{Recruitment.}

Participants in this study represent an opportunistic sample who were recruited from a mixed methods study conducted by the authors. Participants in the original study were asked to complete standardised outcome measures and attend an interview asking them about their experience of participation in a music therapy group. An additional interview question asking participants about their experience of completing the self-report outcome measures used in the research study was added after participants reported difficulty completing the measures during data collection. Consumers receiving community treatment from an adult mental health service in the North-Eastern suburbs of Melbourne, Australia were given information about the original study. Mental health workers and case managers were involved in recruiting participants to the study over a two month period by distributing flyers to consumers. Ethics approval was received for this project by the St. Vincent's Hospital Melbourne Human Research Ethics Committee A and the University of Melbourne Human Research Ethics Committee. Initially, eight participants agreed to be involved in the study. However, four of the eight participants withdrew from the research due to physical illness (1), work commitments (1) and loss of interest (2). The four participating consumers (seen in Table 1) had a long history of mental illness for over 
25 years. Two out of the four participants (Jazz and Martin) chose to be referred to by pseudonyms, while Alexandra and Phillip chose to be referred to by their real name.

\begin{tabular}{|l|l|l|l|l|}
\hline & Phillip & Martin & Jazz & Alexandra \\
\hline Age & 53 & 51 & 51 & 41 \\
\hline Gender & Male & Male & Male & Female \\
\hline Diagnosis & Schizophrenia & Schizophrenia & Schizophrenia & $\begin{array}{l}\text { Bipolar } \\
\text { Disorder }\end{array}$ \\
\hline
\end{tabular}

Table 2. Participant Demographics.

\section{Data collection.}

Individual semi-structured interviews were conducted with each of the four participants. Participants were asked about their experience of completing the selfreport outcome measures during their participation in the music therapy research study. Interviews were audio recorded and transcribed by the first author. The researchers aimed to understand the views of the four consumers who participated in this specific research study and therefore did not seek to recruit more participants. It was not the intention of this study to gain varied perspectives on mental health consumers' experiences of completing standardised outcome measures. Instead, the aim was to understand the perspectives of the four consumers who completed the outcome measures in the current music therapy research study.

\section{Data analysis.}

Each interview was transcribed by listening back to the audio recording. During this process it was important for the researchers to consider the context surrounding what was said by the participant and reflect on the intention of the language used. Reflexivity is understood as an essential element in qualitative research which provides insight into how knowledge is developed (Pillow, 2003). In 
this study reflexivity offered clarity around the links between the data, analysis and presentation of the findings.

Descriptive phenomenological microanalysis was used to analyse the interview data. This form of qualitative analysis is informed primarily by Giorgi's (1975) procedural approach to phenomenological analysis. This method was chosen in an attempt to generate a descriptive account of each participants experience, and to prioritise their voice. The analysis was a four step process adapted from McFerran and Grocke's (2007) microanalysis process, which included: 1) identifying key statements to reduce the data to its essential elements, 2) classifying data into topics/categories (defined as Structural Meaning Units), 3) reconstructing the data to capture the meaning in the descriptions, following a long time of immersion in the interview transcripts (defined as Emotional Meaning Units), and 4) creating an individual distilled essence for each participant in the form of a narrative that aims to capture the essential features of each participants' experience. Table 2 presents the main themes and categories identified during step two and three of the analysis. The software package NVivo (QSR International Pty Ltd. Version 10, 2014) was helpful in the analysis process to highlight certain phrases and words and group similar ideas together. The codes (termed Emotional Meaning Units) identified in step three were combined in step four to form an individual distilled essence for each participant, which is presented as a narrative in the results section. The perspective of the primary author who assisted participants in completing the outcome measures is also presented in the results section as a way of triangulating the data. Triangulation is a research technique which facilitates the verification of the data by collecting two or more perspectives on the same phenomenon (Creswell \& Plano Clark, 2011). In this case, the primary researcher's observations of the completion of the outcome measures are 
offered alongside each distilled essence in an attempt to provide a sense of the context that was apparent during the research process and to validate the interview data.

\begin{tabular}{|c|c|c|c|c|}
\hline & Jazz & Phillip & Martin & Alexandra \\
\hline $\begin{array}{l}\text { Structural Meaning } \\
\text { Units }\end{array}$ & $\begin{array}{l}\text { Challenges in } \\
\text { memory } \\
\text { Researcher } \\
\text { assistance } \\
\text { Guessing }\end{array}$ & $\begin{array}{l}\text { Unfamiliarity } \\
\text { Time } \\
\text { Clarity }\end{array}$ & $\begin{array}{l}\text { Difficulty } \\
\text { Researcher } \\
\text { assistance }\end{array}$ & $\begin{array}{l}\text { Desire to provide } \\
\text { feedback } \\
\text { Mental state } \\
\text { Language used } \\
\text { requires explanation } \\
\text { Using strategies } \\
\text { Researcher } \\
\text { assistance } \\
\text { Familiarity }\end{array}$ \\
\hline $\begin{array}{l}\text { Emotional Meaning } \\
\text { Units }\end{array}$ & $\begin{array}{l}\text { It is difficult to } \\
\text { remember } \\
\text { When I couldn't } \\
\text { remember, I just } \\
\text { made it half way } \\
\text { between } \\
\text { It makes it easier } \\
\text { when you read them } \\
\text { out }\end{array}$ & $\begin{array}{l}\text { A lot of points were } \\
\text { unfamiliar } \\
\text { The answers only } \\
\text { differed a little } \\
\text { They need a lot of } \\
\text { time } \\
\text { They were succinct } \\
\text { and clear }\end{array}$ & $\begin{array}{l}\text { I would have had } \\
\text { more problems } \\
\text { completing them by } \\
\text { myself } \\
\text { They were difficult } \\
\text { The scale about the } \\
\text { music group made } \\
\text { sense }\end{array}$ & $\begin{array}{l}\text { I want to make sure } \\
\text { that I get it } \\
\text { I want my feedback } \\
\text { to be valued } \\
\text { It is different when I } \\
\text { am doing better } \\
\text { mentally } \\
\text { Knowledge of the } \\
\text { definitions would be } \\
\text { helpful } \\
\text { I have strategies that } \\
\text { I use to make them } \\
\text { easier to complete } \\
\text { I could take forever } \\
\text { doing this on my } \\
\text { own } \\
\text { You get more } \\
\text { familiar with them } \\
\text { after the second or } \\
\text { third time }\end{array}$ \\
\hline
\end{tabular}

Table 2. Themes and Distilled Essences.

\section{Results}

In this section, participants' individual distilled essences are presented along with reflections written by the primary author in reflexive journal entries. Each distilled essence aims to capture the voice of the participant by using their own words and reflecting the amount of material that was discussed in the interview. Each 
sentence in the essence represents a different Experienced Meaning Unit or 'theme' from the participants' responses. The primary researcher's observations are also included in order to provide a sense of the context that was apparent during the research process. Participants' own words are indicated in the researcher's reflections through quotation marks.

\section{Phillip.}

\section{Researcher's reflection.}

Phillip completed the questionnaires himself and took 90 minutes in total to complete the questionnaires on all three occasions. There were times when he would sit still for ten minutes or so with the pen in his hand, seemingly thinking about a question. During these times I asked Phillip if he would like assistance or if he was unsure of what the question was asking him. He declined the offer stating, "no, no, I'm ok" and after another few minutes circled an answer on the page. On the second and third occasions it seemed as though Phillip may have memorised some of his responses from the first time he completed them, as seen by the time he took to think about each question.

\section{Phillip's narrative.}

I think they were straight forward, but I think they were searching as well, a lot of points were sometimes unfamiliar. They needed a lot of time, so that I could think about it, but not an excessive amount of time. Sometimes the answers were a little bit different from the last question, but apart from that they were quite succinct and clear. 


\section{Researcher's reflection.}

On all three occasions, Jazz expressed an initial reluctance to complete the questionnaires, stating, "there seems like an awful lot here" and "I'm not good with forms." With support and reassurance, Jazz was able to complete all measures given to him. He accepted my offer to read the questions out to him so he could just tick the box on the page. Jazz sighed a lot while completing the measures and shuffled in his seat. He seemed to be rushing through the questions and had a tendency to mark the middle option on the page.

\section{Jazz's narrative.}

It is hard to remember things in the last week. It was alright. It is just a bit of an effort to remember things. When I could not remember I just sort of made the answer half way between. I understood most of the questions, it made it a bit easier when the researcher read them out.

\section{Martin.}

\section{Researcher's reflection.}

Martin accepted my offer to read the questions out to him on all three occasions of completing the questionnaires. For many of the questions Martin asked me what they were asking him, stating "I don't understand." After I attempted to explain and reframe the question, Martin still did not seem to understand the questions but circled an answer on the page anyway. Martin would often read his answers to the questions out loud to me, seemingly seeking reassurance that his answers were 'correct'. 


\section{Martin's narrative.}

Yeah the questionnaires were a bit difficult actually, especially the first two. The third one, that made sense, the one about the music group. Maybe it was the bigger distribution on the scale, no it was not that. I am not sure. At first I thought the questions weren't making sense but I might have had more problems completing them by myself.

\section{Alexandra. \\ Researcher's reflection.}

Alexandra strongly desired to advocate for others with mental illness and believed in the importance of research in this area. Each time Alexandra completed the measures, she spent time marking the questions she did not understand and wrote down suggestions or comments 'to be considered' by the researchers. The first and second time she completed the measures, she tried made sure that she understood the questions being asked of her and requested clarification in order to achieve this. The second time she completed them she was more mentally unwell and seemed to get stuck on questions frequently. On this occasion she was very literal about each word written on the page and suggested that the questionnaires be "improved" so they were "easier to understand." Alexandra also suggested that perhaps she did not understand the questions in some of the measures because she was an "amateur." During the interview, Alexandra had a lot to say about her experience of completing the questionnaires. We went through each of her suggestions and the comments she had written down and discussed these along with her general experience of the group.

\section{Alexandra's narrative.}

After doing the questionnaires the second or third time, you get more familiar with them. I instantly think of examples and circumstances in my real world to help 
me when I am answering the questions. I could take forever doing them on my own, it would not necessarily be any better, it would just feel a bit tiring. I am all for having a little list of definitions of terms in the questionnaires. If I was not doing well, I would find that useful. I am less needy of exactness now that I am doing better mentally. I want to make sure that I get it and I am giving reliable information. You know when you want your thoughts and opinions valued? I like to think that what we put down as feedback about the questionnaires will affect future research.

\section{Discussion}

The four participants in this study provided individual reports on their experience of completing standardised outcome measures in a research project, which support the findings of literature in this field. Jazz, Phillip and Alexandra reported difficultly recalling information and concentrating on the measures they were asked to complete. Jazz found it hard to remember things that he was asked. People with severe mental illness can experience cognition and memory issues which can make it difficult to think back in time (American Psychiatric Association, 2013). Phillip commented on the unfamiliarity of some of the questions and how he needed a lot of time, so that he could think about his responses. All four of the participants took much longer to complete the outcome measures than estimated. Focusing for long periods can be difficult for people with severe mental illness who experience symptoms which can affect their ability to concentrate. Consumers have previously reported that the more questions they are asked to answer in an outcome measure, the less amount of time and attention they spend on their response (Stasiak et al., 2012).

Alexandra recommended including a list of definitions of terms in the outcome measures so that participants could refer to this in an attempt to better understand the words in each question. Long, complex words and clinical jargon is 
often difficult for people with mental illness to understand. Language which is "straightforward," "comprehensible" and "in a form [consumers] can understand" is understandably preferred by participants with mental illness (Stasiak et al., 2012, p. 526). In Hoy (2014)'s study which explored consumers' experiences of completing a standardised self-report measure of recovery, all 17 participants reported difficulty in understanding the questions asked in the self-report outcome measures. All of the participants reported feeling the need to ask someone for assistance so they could understand what the questions meant. Similarly, Jazz, Martin and Alexandra referred to the support they received during the research as making the data collection process easier. Alexandra and Martin thought they would have more difficulty and feel tired if they had to complete the outcome measures on their own. Jazz referred to the process being easier when the researcher read the questions out to him. In their recommendations regarding the use of standardised self-report measures in a community mental health setting, Greeno and colleagues (2007) suggest conducting outcome measures in an interview style with mental health consumers. These authors argue that reading the questions out to participants reduces literacy burden, so that they are more likely to understand the questions they are being asked.

One of the outcome measures participants were asked to complete in this study, the CORE questionnaire, has been validated for use in psychology and counseling programs with people experiencing mental illness in the community (Gray \& Mellor-Clark, 2007). However, in an earlier study the authors caution future users of the measure stating:

We distinguish clearly between patients seen in out-patient settings within secondary care services (as reported here) and patients deemed to be within a category that has been referred to as 'serious and enduring mental illness'. 
For such patients, the process of understanding and completing a self-report measure might yield results that are not necessarily continuous with those reported here (Barkham, Gilbert, Connell, Marshell \& Twigg, 2005, p. 245). There is no reference in the article as to what is considered a 'serious and enduring mental illness.' However, Jazz, Phillip, Alexandra and Martin all had a severe mental illness for more than 25 years, which could explain why they had difficulties completing the measure.

The Perceived Cohesion in Small Groups scale (PCiSG) has only been tested in a non-clinical sample of university students but was used in this study due to the lack of other measures with a small number of items measuring belonging in a small group context. This likely explains why the questions appeared to be cognitively challenging for participants in the current study to understand. The limited number of reliable and validated self-report measures for participants with severe mental illness has serious implications for research in this field. Future creators of such measures may benefit from collaborating with consumers to identify language that is more easily understood by people with severe mental illness.

The authors recently conducted a critical review of the self-report measures most commonly used in Australian mental health research in the last ten years (Bibb, Baker \& McFerran, 2016). Results found that only two out of the top seven most commonly used self-report tools in Australian mental health research in the last ten years were developed from a consumer perspective. This is surprising given the recent emphasis on consumer involvement in contemporary mental health research and the importance placed on lived experience. The perspectives of the participants in this study provide support for the importance of using clear and common language in self- 
report outcome measures. This is important for both increasing accuracy of the data collected and fostering positive experiences of data collection for participants.

Participants in the current study reported experiences congruent with schizophrenia and bipolar disorder. The Sense of Belonging Instrument (SOBI-A and SOBI-P) was validated with consumers from inpatient and outpatient settings with major depression, and although this can similarly result in reduced mental capacity (American Psychiatric Association, 2013), presents differently to schizophrenia and bipolar disorder. It is also important to note that the measure was created by "experts in the field" (Hagerty \& Patusky, 1995, p. 10). This expert involvement may explain why participants had trouble completing the measure and were not able to understand the language used in the items. One participant (Alexandra) was able to explain that she needed to take time, breaking down the questions in this measure in order to understand what was being asked of her. The quality of questions asked of participants in research, influences the quality of data we collect from them (Chase, 2003). The professional and unclear language used in self-report outcome measures can increase the division of power between participants and researchers, potentially disempowering mental health consumers through the research process (Bibb, Baker \& McFerran, 2016).

The evaluation of community mental health programs has been traditionally based on measurement of change. However, the difficult experience of outcome measure completion described by participants in this study highlights a number of challenges in metrically capturing change for people with severe mental illness. Yet these same people were able to describe positive experiences of the music therapy program in interviews by using their own words (Bibb, Baker, Tamplin \& McFerran, under review). The small number of participants in this study make it difficult to 
apply these findings to other contexts, but this study offers interesting insights into four consumers' experiences of the research process. Future research is needed in this area so that researchers are aware of the potential negative effects the research process can have on participants, and to ensure that consumers experience research participation as a unique opportunity to be heard (Grant, 2015).

The participants in this study were an opportunistic sample and represent an idiographic account of four consumers' experience of completing specific outcome measures in a mixed methods research study. As such, the findings are not generalisable to consumers outside of this sample. Future research would benefit from recruiting a varied sample of consumers who have participated in research using outcome measures in order to offer a more diverse range of perspectives on the phenomenon.

\section{Conclusion}

This study revealed that completing measures in order to determine change deserves careful consideration. Each of the four participants in this study struggled to complete a number of self-report outcome measures for individual reasons. The language in the measures used in this study was reported as difficult to understand by participants. One participant was even able to articulate the nature of her disempowerment during the data collection process. Watching these consumers who had a positive experience of a music therapy program, struggle and appear disempowered by the data collection process was disappointing and made us doubt the validity of the answers. Future research in this area should consider the congruence between using self-report outcome measures and recovery-based principles in order to ensure that participation in research is not disempowering. 


\section{References}

American Psychiatric Association. (2013). Diagnostic and statistical manual of mental disorders (5th ed.). Washington, DC: Author.

Barkham, M., Gilbert, N., Connell, J., Marshell, C., \& Twigg, E. (2005). Suitability and utility of the CORE-OM and CORE-A for assessing severity of presenting problems in psychological therapy services based in primary and secondary care settings. British Journal of Psychiatry, 186, 249-256.

Bibb, J., Baker, F., A., \& McFerran, K., S. (2015). A critical interpretive synthesis of the most commonly used self-report measures in Australian mental health research. Australasian Psychiatry. doi:10.1177/1039856215626646

Bibb, J., Baker, F. A., Tamplin, J., \& McFerran, K. S. (under review). Experiences of belonging within a small community-based therapeutic singing group for four people in mental health recovery.

Boothroyd, R. (2000). The impact of research participation on adults with severe mental illness. Mental Health Services Research, 2(4), 213-221.

Carey, M., Morrison-Beedy, D., Carey, K., Maisto, S., Gordon, C., \& Pedlow, C. (2001). Psychiatric outpatients report their experiences as participants in a randomized clinical trial. Journal of Nervous \& Mental Disease, 189(5), 299-306.

Chase, S. E. (2003). Up close and personal: The teaching and learning of narrative research. In R. Josselson, A. Lieblich \& D. P. McAdams (Eds.), The narrative study of lives (pp. 79-99). Washington DC, USA: American Psychological Association.

Creswell, J. W., \& Plano Clark, V. L. (2011). Designing and conducting mixed methods research (2nd ed.). Thousand Oaks: Sage Publications. 
Dunn, L., Candilis, P., \& Weiss-Roberts, L. (2006). Emerging empirical evidence on the ethics of schizophrenia research. Schizophrenia Bulletin, 32(1), 47-68.

Dworkin, R. (1992). Researching persons with mental illness. Newbury Park, CA: Sage.

Giorgi, A. (1975). An application of phenomenological methods in psychology. In A. Giorgi, C. T. Fisher, \& E. L. Murray (Eds.). Dusquesne Studies in Phenomenological Psychology (2 ${ }^{\text {nd }}$ ed.). Pittsburough: Dusquesne University Press.

Grant, S. (2015). The experiences of research participants living with schizophrenia. Social Work in Mental Health, 13, 532-552. doi:10.1080/15332985.2014.984887

Gray, P., \& Mellor-Clark, J. (2007). CORE: A decade of development. Rugby: CORE IMS.

Greeno, C. G., Colonna-Pydyn, C., \& Shumway, M. (2007). The need to adapt standardized outcome measures to community mental health. Social Work in Public Health, 23(2), 125-138.

Hagerty, B. M. K., \& Patusky, K. (1995). Developing a measure of sense of belonging. Nursing Research, 44(1), 9-13.

Hoy, J. (2014). The space between: Making room for the unique voices of mental health consumers within a standardized measure of mental health recovery. Administration and Policy in Mental Health, 41, 158-176. doi:10.1007/s10488-012-0446-4

Kaminsky, A., Roberts, L., \& Brody, J. (2003). Influences upon willingness to participate in schizophrenia research: An analysis of narrative data from 63 people with schizophrenia. Ethics and Behavior, 13(3), 279-302. 
Labott, S., \& Johnson, T. (2004). Psychological and social risks of behavioral research. IRB Ethics \& Human Research, 26(3), 11-15.

Marshall, R., Spitzer, R., Vaughan, S., Vaughan, R., Mellman, L., MacKinnon, R., \& Roose, S. (2001). Assessing the subjective experience of being a participant in psychiatric research. American Journal of Psychiatry, 158, 319-321.

McFerran, K., \& Grocke, D. (2007). Understanding music therapy experiences through interviewing: A phenomenological analysis. In T. Wosch, \& T. Wigram (Eds.). Microanalysis in music therapy (pp. 273-284). London: Jessica Kingsley Publishers.

Muhammad, M., Wallerstein, M., Sussman, A., L., Avila, M., Belone, L., \& Duran, B. (2015). Reflections on researcher identity and power: The impact on positionality on community based participatory research (CBPR) processes and outcomes. Critical Sociology, 41(7-8), 1045-1063.

doi:10.1177/0896920513516025

Pillow, W. (2003). Confession, catharsis, or cure? Rethinking the uses of reflexivity as methodological power in qualitative research. International Journal of Qualitative Studies in Education, 16(2), 175-196.

doi:10.1080/0951839032000060635.

Shaw, J., \& Epstein, M. (1996). The rat speaks back: A consumer perspective of the research process. There is a Person in Here: Proceedings of the $5^{\text {th }}$ Annual THEMHS Conference (pp. 280-283). Victoria: The Mental Health Services Conference Inc. of Australia and New Zealand.

Silverman, M. J., \& Leonard, J. (2012). Effects of active music therapy interventions on attendance in people with severe mental illnesses: Two pilot studies. Arts in Psychotherapy, 39(5), 390-396. doi:10.1016/j.aip.2012.06.005 
Stasiak, K., Parkin, A., Seymour, F.,...et al. (2012). Measuring outcome in child and adolescent mental health services: Consumers' views of measures. Clinical Child Psychology and Psychiatry, 18(4), 519-535. 


\section{University Library}

\section{- M M N E R VA A gateway to Melbourne's research publications}

Minerva Access is the Institutional Repository of The University of Melbourne

Author/s:

Bibb, J;McFerran, KS

Title:

The Challenges of Using Self-Report Measures with People with Severe Mental IIIness: Four Participants' Experiences of the Research Process

Date:

2017-08-01

Citation:

Bibb, J. \& McFerran, K. S. (2017). The Challenges of Using Self-Report Measures with People with Severe Mental Illness: Four Participants' Experiences of the Research Process. COMMUNITY MENTAL HEALTH JOURNAL, 53 (6), pp.747-754. https://doi.org/10.1007/ s10597-017-0127-6.

Persistent Link:

http://hdl.handle.net/11343/282650 